\title{
DA INQUIRIBILIDADE À CRIAÇÃO: AS DESCOBERTAS E A INTER-RELAÇÃO COM O SONORO DESDE A PRIMEIRA INFÂNCIA
}

\section{FROM INQUIRIBILITY TO CREATION: THE DISCOVERIES AND THE INTERRELATIONSHIP UITH THE SONOROUS FROM AN EARLY CHILDHOOD}

\author{
Cláudia Jaqueline de Souza Siufi \\ Universidade de São Paulo \\ claudiasiufi@usp.br
}

Silvia Maria Pires Cabrera Berg

Universidade de São Paulo

silviaberg@usp.br

\section{Resumo}

Este artigo apresenta um estudo de caso relatando experiência realizada em aulas de música de Educação Infantil na escola regular, envolvendo alunos entre um e cinco anos de idade, suas inter-relações com o sonoro e desenvolvimento da criatividade. Partindo dos conceitos de François Delalande a respeito da exploração e criação musical através de objetos sonoros, identificamos nesta pesquisa conexões com Walter Howard que também apresenta estudos na área. Concluímos que a ampliação das relações com os sons a partir da inquiribilidade, exploração e investigação aguça a criatividade e abre caminho para o desenvolvimento de habilidades essenciais ao longo da infância.

Palavras-chave: educação musical; educação infantil; criatividade; percepção sonora; primeira infância. 


\section{Abstract}

This paper presents a case study reporting experiments performed in early childhoods Music Education classes in regular schools, involving students from one to five years old, their relationships with the sounds and the development of creativity. Based on the concepts of François Delalande about exploitation and musical creation through sound objects, we identified in this research, connections with Walter Howard who also presents studies in the area. We conclude that the expansion of relations with the sounds from the inquiribility, exploration and research sharpens creativity and paves the way for the development of essential skills throughout childhood.

Keywords: musical education; child education; creativity; sound perception; early childhood.

\section{Introdução}

A descoberta faz parte do mundo infantil desde o nascimento. Ativa e criativa a criança testa e elabora hipóteses diante de tudo o que the é exposto no seu dia a dia. "O ato da criança é científico: primeiro ela estuda os elementos constitutivos daquilo que se the apresenta. Para começar, reage aos fenômenos isolados antes de estabelecer relações entre eles." (Howard, 1984). Neste sentido, entendemos que a interação da criança com a linguagem musical deva ocorrer desde cedo a partir da exploração, da pesquisa e da criação, por meio da integração entre sujeito e objeto.

Partimos do princípio de que o trabalho com música na Educação Infantil deve trilhar um caminho aberto e criativo por meio de uma pedagogia do despertar que visa à investigação, exploração, percepção e criação. Delalande (2013) cita que:

A pedagogia musical a que nos referimos se propõe conduzir a criança do descobrimento e exploração de fontes sonoras, à invenção e à criação. No transcurso deste caminho, ela aprenderá a construir uma sequência com 
sons, a expressar-se através deles, a escutar, a exercitarse em fazer e ouvir. (DELALANDE, 2013, p. 151; tradução nossa)!

Apresentamos neste artigo um relato de experiência realizada com alunos entre um e cinco anos de idade baseada nos conceitos de François Delalande, defensor da ideia de que se deve propiciar à criança um contato precoce com instrumentos musicais e objetos sonoros incentivando-as a produzir sons com movimentos espontâneos de criação.

É na escola, partindo da educação infantil, que podemos iniciar um caminho de despertar, de sensibilizar, fazendo com que as crianças se tornem um solo fecundo desenvolvendo nelas um sólido desejo pelo aprender musical. A ideia de uma pedagogia de criação musical proposta por Delalande se concebe como uma abertura para os aspectos mais universais da música, através de uma busca que vem da criança e sua inter-relação com o sonoro, ainda sem uma preocupação de orientação estética de seus descobrimentos.

Segundo Delalande, as sequencias sonoras que as crianças de menos de seis anos produzem, ainda estão muito marcadas pela exploração das fontes ou pelo desejo de simbolizar diretamente uma cena. Já a preocupação em organizar a música para the dar uma forma, surge mais tarde, quando o respeito à regra domina o jogo da criança.

[...] o jogo simbólico permite à criança, desde o segundo
ano de vida, mas, sobretudo entre os três ou quatro anos,
utilizar o som com a finalidade de representação e de
expressão [...]; o jogo de regras que favorece sobretudo
entre os cinco e seis anos, o interesse pelas combinações
sonoras, as regras formais e a distribuição de papéis no
jogo coletivo. É uma sucessão de interesses tão fortes na
criança que seria absurdo não fazer disso o ponto de

I La pedagogía musical a la que nos referimos se propone conducir al niño del descubrimiento y la exploración de fuentes sonoras a la invención y la creación. En el transcurso de este camino él aprenderá a construir una secuencia con los sonidos, a expresarse a través de ellos, a escuchar, a ejercitarse en hacer y en oír. (DELALANDE, 20 I3, p. 151) 
apoio de uma pedagogia musical. (DELALANDE, 2013, p.

157; tradução nossa)²

Ao longo do desenvolvimento do projeto realizado com as crianças pode-se observar e comprovar todas estas ideias defendidas por Delalande.

\section{A criação, o sonoro e a criança}

Segundo o dicionário contemporâneo da língua portuguesa, a curiosidade é o interesse pelo conhecimento ou investigação de determinado assunto. Sendo assim, podemos dizer que a curiosidade é a capacidade natural e inata da inquiribilidade, a capacidade humana de ver ou querer conhecer algo até então desconhecido, que motiva a exploração, a investigação e o aprendizado.

Segundo Retondar (RETONDAR; MATTOS, 2011 ), o ato de criação é o movimento realizado pelo sujeito diante de uma nova possibilidade. Entusiasmada $e$ investigadora, a criança ao ser estimulada, pode vir a ser o artista por excelência, pois segundo Gilles Deleuze (DELEUZE apud RETONDAR, idem), a liberdade para criar funciona como um explosivo. "Ela é capaz de subverter as regras da lógica e do conhecimento mergulhando na força do pensamento criativo." (RETONDAR; MATTOS, 2011 ).

Logo ao nascer, a criança está atenta a todos os sons ao seu redor, observa o tom com que a mãe, a babá ou outros habitantes da casa falam e como agem em sua presença. Segundo Howard (1984), “É suficiente uma semana para que o nenê conheça a babá de cada dia e saiba como deva se comportar para dela obter tudo o que desejar."

De maneira investigativa e exploratória, a criança produz e faz música desde sempre. Há pesquisas que indicam o balbucio dos

2 “.... el juego simbólico que permite al niño, desde el segundo año de vida, pero sobre todo hacia los 3 o 4 años, utilizar el sonido con fines de representación y de expresión [... ]; y el juego de reglas que favorece, sobre todo hacia los 5 ó 6 años, el interés por las combinaciones sonoras, las reglas formales y la distribución de roles en el juego colectivo. Es una sucesión de intereses tan fuertes en el niño que sería absurdo no hacer de ello punto de apoyo de una pedagogía musical." (DELALANDE, 2013, p. 157) 
bebês como as primeiras experiências sonoras a partir interação com seu próprio corpo. "Antes de ser exclusivamente mental, a recepção da música é em primeiro lugar, corporal." (DELALANDE, 1995, p.62; tradução nossa). ${ }^{3}$ Enquanto cresce, estas experiências se intensificam ampliando o seu repertório de sons.

Ao longo do caminhar da infância e como consequência de sua relação com o ambiente, as crianças criam ideias de música e constroem seu fazer musical. Teca Alencar de Brito afirma que:

A criança é um ser brincante e, brincando, faz música, pois assim se relaciona com o mundo que descobre a cada dia. Fazendo música, ela, metaforicamente, "transforma-se em sons'. Num permanente exercício, receptiva e curiosa, a criança pesquisa materiais sonoros, 'descobre instrumentos', inventa e imita motivos melódicos e rítmicos. (BRITO, 2004)

Cada vez mais cedo as crianças tem acesso à escola e é neste espaço que são estimuladas e incentivadas a novas descobertas desenvolvendo-se física, cognitiva e socialmente. Howard confirma esta ideia quando diz que "É preciso trabalhar o aluno como uma pessoa inteira, com sua afetividade, suas percepções, sua expressão, seus sentidos, sua crítica, sua criatividade..." (HOWARD, 1984). As aulas de música devem abrir espaço para a elaboração de hipóteses e comparação de possibilidades, ampliando recursos e respeitando os interesses, a motivação, a maturidade e toda a bagagem cultural que cada aluno traz consigo. John Cage também reafirma o que acreditamos quando diz que "A música não é só uma técnica de compor sons e silêncios, mas um meio de refletir e de abrir a cabeça do ouvinte para o mundo." (CACE apud BRITO, 2007)

Para Delalande, os alunos da Educação Infantil são "músicos concretos" natos. Descobrem utensilios, corpos sonoros quaisquer; exploram o material, veem o que se pode tirar destes e tratam de gerar toda uma familia de sons que pareçam entre si. "[...] prolongam sua exploração produzindo variações: e é aí que se comportam como

3 "Antes de ser exclusivamente mental, la recepción de la música es en primer lugar, corporal". (DELALANDE, 1995: p. 62) 
verdadeiros músicos. " (DELALANDE, 1995, p. 44; tradução nossa)4

Educar as crianças não é tira-los de um estado de nada musical no qual se supõe que estejam para leva-los a certo nível de competência, mas pelo contrário, desenvolver uma atividade lúdica que existe entre eles e que é finalmente a mesma fonte do jogo, a execução musical. (DELALANDE, 1995, p. 15; tradução nossa) $)^{5}$

\section{A exploração sonora, a criação e o fazer musical na Educação Infantil: relato de experiência.}

Sendo a música entendida como um processo contínuo de construção que envolve perceber, sentir, experimentar, imitar, criar e refletir desenvolvemos um projeto com alunos de Educação Infantil na escola regular, com idades entre um e cinco anos em que o principal objetivo era permitir às crianças um contato livre com corpos sonoros diversos, abrindo espaço à inquiribilidade e à expressividade no fazer musical infantil. Neste sentido, propusemos um trabalho de investigação sonora com materiais diversificados como papéis, objetos plásticos e de metal, onde se buscava sentir e apreciar o movimento do som e dos ruidos, sendo o interesse e a investigação auditivos, guias da exploração. Também tínhamos como meta, além da exploração, pequenas organizações e produções sonoras elaboradas pelos próprios alunos.

A escolha dos materiais que seriam utilizados no desenvolvimento do projeto foi realizada partindo de fontes sonoras diversas, primando às diferenças sonoras e de timbre explorado em cada objeto. Optou-se por papéis de diferentes tipos e texturas, objetos plásticos com formas e tamanhos diversificados, plástico bolha e chapas de raios- $X$, além de objetos de metal como panelas, frigideiras, latas, travessas, colheres e outros.

4 “....) prolongan su exploración produciendo variaciones: es en eso donde se comportan como verdaderos músicos." (DELALANDE, 1995, p. 44)

5 "Educar a los niños no es sacarlos de un estado de nada musical en el que se supondría que están, para llevarlos a un cierto nivel de competencia, sino, por el contrario, desarrollar una actividad lúdica que existe entre ellos y que es finalmente la fuente misma del juego, la ejecución musical." (DELALANDE, 1995, p. 15) 
Cada material foi trabalhado durante quatro encontros aproximadamente, sempre dentro da sala de música. Os alunos eram recebidos já com o ambiente preparado, com os materiais que seriam explorados já dispostos pela sala. Ao entrar, as crianças primeiramente eram orientadas a observar visualmente os materiais. A observação visual durava muito pouco, pois a curiosidade para a exploração sonora era mais forte. Estes materiais deveriam ser explorados livremente em todas as suas possibilidades: amassados, raspados, sacudidos, rasgados, batidos, esfregados, e outras ações descobertas; dando-se expressiva atenção aos sons produzidos nas diferentes formas de manuseio.

A primeira aula constou de livre exploração e manuseio sem intervenções quaisquer. No segundo encontro, os alunos foram convidados a mostrar aos colegas os sons que haviam descoberto no manuseio dos objetos. Depois, eram desafiados a criar pequenas composições ou sequencias sonoras, misturando timbres e outros parâmetros do som, como intensidade e/ou duração. Nas aulas seguintes, os materiais foram utilizados para sonorização de histórias criadas pelos próprios alunos, instrumentação de músicas do folclore ou reprodução de sons da natureza.

As crianças tiveram total liberdade para interagir com os objetos descobrindo diferentes formas de manuseio e com isso, sons e ruídos foram surgindo. $O$ prazer de poder bater forte num objeto ou rasgar e amassar um papel sem que ninguém os repreendesse foi essencial para perceber que os sons se modificam na medida em que as ações sobre os objetos são distintas. A construção do aprendizado se deu a partir dessas experiências básicas e essenciais. Possibilitou-se aí um contato diferente com a música, onde a inquiribilidade, a investigação e a livre exploração foram os guias do trabalho tornando os alunos dessa maneira, protagonistas da própria aprendizagem.

Ao longo do Projeto, surgiram outras propostas tais como: desafios musicais onde novos sons deveriam ser encontrados sob um mesmo objeto e composições de materiais que deveriam ser organizados para novas experimentações e arranjos sonoros. Debateu-se sobre as diferenças sonoras ouvidas e fez-se analogias a sons já conhecidos. Gravações eram realizadas através de vídeos ou somente áudio, tanto das produções individuais quanto das coletivas, mostrando-as depois para que as crianças se vissem e pudessem se ouvir, abrindo-se espaço para pequenas discussões sobre o que produziram. Durante 
quatro meses com total liberdade, sem medo de errar e sem restrições, as crianças mexiam, remexiam, viravam, rasgavam, batiam, esfregavam e se encantavam com tudo aquilo que descobriam e produziam.

Toda a exploração musical é espontânea. A criança, ou mesmo um adulto que é exposto a um corpo sonoro novo tende a ser impulsionado pela curiosidade, observando e testando, fazendo um inventário de todos os recursos que este oferece. Sendo assim, a motivação pela descoberta deve fazer parte de todo o conteúdo educativo por meio de uma pedagogia musical baseada na busca sonora que tem seu momento mais propício na primeira infância.

\section{Conclusão}

A criação e o pensamento caminham juntos e é através do desenvolvimento da criatividade que se possibilita a liberdade de pensamento. Neste sentido, entendemos que a relação da criança com a música pode ser muito maior quando se tem a oportunidade de ser o protagonista do próprio aprendizado. Partindo de experiências de exploração e investigação sonora percebe-se que há um ganho não só na área artística, mas na construção do indivíduo como um todo, abrindo caminho para o desenvolvimento de outras habilidades essenciais à formação da criança na primeira infância. Perceber que não existe certo ou errado na exploração musical e na criação, faz com que a criança desenvolva autoconfiança, melhore a autoestima e amplie sua percepção de mundo.

A partir deste Projeto, as crianças mudaram sua relação com os sons tornando-se mais atentas ao que lhes rodeia, ao explorar tudo à sua volta que pudesse produzir sons: criavam ritmos, descobriam diferenças sonoras e orgulhosamente chamavam a atenção dos outros para suas produções. Percebeu-se também grande benefício no que diz respeito à ideia de música que os adultos trazem consigo. Ao acompanhar o trabalho dos alunos, toda a comunidade escolar começou a ampliar seus conceitos musicais abrindo espaço para os "ruídos", respeitando as criações sonoras produzidas, reconhecendo assim, as crianças como fontes inesgotáveis de criatividade. 


\section{Referências}

AULETE, Caldas. Novissimo Aulete dicionário contemporâneo da lingua portuguesa. - Organizador Paulo Geiger. Rio de Janeiro, Lexikon, 2011

BRITO, Teca, Alencar de. Música na Educação Infantil: propostas para formação integral da criança. $2^{\circ}$ ed. São Paulo, Peirópolis, 2003

BRITO, Maria Teresa A. de. Por uma educação musical do pensamento: novas estratégias de comunicação. São Paulo, Universidade de São Paulo, 2007

DELALANDE, François. Las Conductas Musicales. Santander, Editorial de la Universidad de Cantabria, 2013

DELALANDE, Fraçois. La música es um juego de niños. Buenos Aires, Ricordi, 1995

HOWARD, Walter. A música e a criança, São Paulo, Summus, 1984

RETONDAR, Jeferson José Moebus; MATTOS, Rafael da Silva. "A criatividade como vontade de potência e como expressão da agressividade no contexto de uma pedagogia humana." Revista filosofia capital, vol. 6, n. 12, p. 14-24, janeiro 2011. 


\section{Sobre as autoras}

Prof ${ }^{a}$. Dra . Silvia Maria Pires Cabrera Berg é compositora e regente paulistana é bacharel em composição pela ECA-USP, pósgraduada na Universidade de Oslo e doutora pela Universidade de Copenhague. Atualmente, é docente do Departamento de Música da FFLCRP-USP, coordenadora do LAPECIPEM e do arquivo Edmar Ferretti, coordenadora do Intercâmbio Acadêmico Internacional com - Bornekorakademiet (Dinamarca) e membro do NAP-CIPEM - do Departamento de Música da FFCLRP-USP.

Cláudia Jaqueline de Souza Siufi trabalha como professora de Educação Musical para Educação Infantil e Ensino Fundamental há vinte anos. Graduada em Pedagogia e pós-graduada em Educação Musical atualmente é mestranda em Música na ECA-USP.

Recebido em 1 1/08/2016

Aprovado em 02/09/2017 